Int. J. Electrochem. Sci., 15 (2020) 3143 - 3156

\title{
Stripping voltammetric determination of Epinephrine applying sulfacetamide modified glassy carbon electrode
}

\author{
T. A. Ahmed ${ }^{1, *}$, M. A. Ghandour ${ }^{2}$, M. M. Khalil ${ }^{1}$ \\ ${ }^{1}$ Chemistry Department, Faculty of Science, Beni-Suef University, Beni-Suef, Egypt \\ ${ }^{2}$ Chemistry Department, Faculty of Science, Assiut University, Assiut, Egypt \\ *E-mail: ali_sorya@yahoo.com
}

doi: $10.20964 / 2020.04 .38$

Received: 10 November 2019 / Accepted: 19 January 2020 / Published: 10 March 2020

In the present work, sulfacetamide (SFA)-modified glassy carbon electrode(MGCE) was successfully constructed by electrochemical modification applying simply cyclic voltammetry (CV) scans. It is well observed that the excellent electrocatalytic ability of SFA film led to much higher oxidation peak current responses compared with bare GCE for epinephrine (EP) oxidation. The EP oxidation takes place at a potential about $120 \mathrm{mV}$ less positive compared with that of an unmodified GCE at the optimum $\mathrm{pH} 5.5$ of phosphate buffer solution (PBS). Applying the anodic stripping differential pulse voltammetry (ASDPV) method and under the optimum conditions, the linear dependence of oxidation peak current on analyte concentrations was found to be $\left(1.0 \times 10^{-7}-1.5 \times 10^{-6}\right) \mathrm{mol} \mathrm{L}^{-1}$, giving detection limit of $2.1 \times 10^{-8} \mathrm{~mol} \mathrm{~L}^{-1}$ and quantification limit of $6.9 \times 10^{-8} \mathrm{~mol} \mathrm{~L}^{-1}$ for EP. The proposed modified electrode exhibited excellent selectivity in the presence of ascorbic acid (AA), glucose (Glu) and uric acid (UA) species whereas dopamine (DA) interfere seriously at higher concentrations. The proposed method showed simplicity, reproducibility, high sensitivity and adequate selectivity. The modified electrode was successfully devoted to EP determination in pharmaceutical formulations and biological fluids; human plasma and urine with acceptable results.

Keywords: Epinephrine; Sulfacetamide; Electrochemical modification; Anodic stripping differential pulse voltammetry

\section{$\underline{\text { FULL TEXT }}$}

(C) 2020 The Authors. Published by ESG (www.electrochemsci.org). This article is an open access article distributed under the terms and conditions of the Creative Commons Attribution license (http://creativecommons.org/licenses/by/4.0/). 